\begin{tabular}{|c|l|}
\hline Title & $\begin{array}{l}\text { Unique [core+two] structure and optical property of a dodecal ligated undecagold cluster : critical contribution of the } \\
\text { exo gold atoms to the electronic structure }\end{array}$ \\
\hline Author(s) & Shichibu, Y ukatsu; Kamei, Y utaro; Konishi, Katsuaki \\
\hline Citation & $\begin{array}{l}\text { Chemical Communications, 48(61), 7559-7561 } \\
\text { https://doi.org/40.1039/c2c30251a }\end{array}$ \\
\hline Issue Date & 2012-08-07 \\
\hline Doc URL & http://hdl.handle.net/2115/52107 \\
\hline Rights & Chem. Commun., 2012,48, 7559-7561- Reproduced by permission of The Royal Society of Chemistry (RSC) \\
\hline Type & article (author version) \\
\hline File Information & Cc48-61_7559-7561.pdf \\
\hline
\end{tabular}

Instructions for use 


\title{
Unique [core+two] structure and optical property of dodeca-ligated undecagold cluster: Critical contribution of the exo gold atoms to the electronic structure $\dagger$
}

\author{
Yukatsu Shichibu, Yutaro Kamei, and Katsuaki Konishi* \\ ${ }_{5}$ Received (in $\left.X X X, X X X\right)$ Xth $X X X X X X X X X 20 X X$, Accepted $X$ th $X X X X X X X X X 20 X X$ \\ DOI: $10.1039 / b 000000 x$
}

A novel dodeca-ligated undecagold cluster having a nonagold core plus two exo-attached gold atoms was synthesized. Unlike the conventional icosahedron-based "core-only" 10 isomer, the $[9+2]$ cluster showed an intense visible absorption band. Theoretical calculation showed the involvement of the exo gold atoms in the generation of the unique electronic structure.

For several decades, there has been considerable interest in 15 the unique structures and properties of geometrically defined gold clusters. ${ }^{1,2}$ The crystal structures of many phosphineprotected clusters have been determined, ${ }^{1,3-6}$ they reveal the metallic moieties generally prefer to form a "core" consisting of fused polyhedra. Herein we report the unusual [core+two] 20 structure of a novel diphosphine-coordinated cluster cation $\left[\mathrm{Au}_{11}\left(\mathrm{Ph}_{2} \mathrm{P}\left(\mathrm{CH}_{2}\right)_{2} \mathrm{PPh}_{2}\right)_{6}\right]^{3+}(\mathbf{1})$, whose $\mathrm{Au}_{11}$ moiety consists of a toroidal $\mathrm{Au}_{9}$ core and two appended gold atoms. The optical profile of 1 was rather different from those of conventional "core-only" clusters, and was characterised by the intense 25 isolated absorption band in the visible region. We also conducted theoretical calculation studies ${ }^{7}$ to demonstrate the critical role of the exo-attached gold atoms in the generation of the unique electronic structure.

The dodeca-ligated $\mathrm{Au}_{11}$ cluster cation (1) was synthesized 30 from the gold complex $\mathrm{Au}_{2}\left(\mathrm{Ph}_{2} \mathrm{P}\left(\mathrm{CH}_{2}\right)_{2} \mathrm{PPh}_{2}\right) \mathrm{Cl}_{2}{ }^{8}$ When the gold salt was reduced by $\mathrm{NaBH}_{4}$ in ethanol at $0{ }^{\circ} \mathrm{C}$, the colourless solution gradually became greenish over time. The addition of $\mathrm{NaSbF}_{6}$ after $1 \mathrm{~h}$ precipitated the cluster product as the hexafluoroantimonate salt, which was further purified

35 by recrystallisation. The electrospray ionization mass spectrum of the cluster species thus obtained shows a set of signals around $\mathrm{m} / \mathrm{z} \approx 1519$, which was unambiguously assigned to the trivalent cluster cation

Faculty of Environmental Earth Science, Hokkaido University, North 10 West 5, Sapporo 060-0810, Japan. Fax: +81 11 7064538; Tel:

+81117064538; E-mail: konishi@ees.hokudai.ac.jp

$\dagger$ Electronic Supplementary Information (ESI) available: Experimental procedures, characterization and crystallographic data, and details of DFT calculations. CCDC 862706. For ESI and crystallographic data in CIF or other electronic format see DOI: $10.1039 / \mathrm{c} 2 \operatorname{cc} 30251 \mathrm{a}$
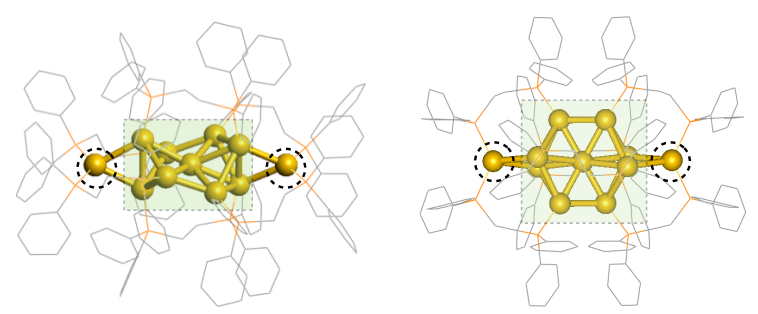

40 Fig. 1 Side (left) and top (right) views of the crystal structure of $\left[\mathrm{Au}_{11}\left(\mathrm{Ph}_{2} \mathrm{P}\left(\mathrm{CH}_{2}\right)_{2} \mathrm{PPh}_{2}\right)_{6}\right]^{3+}$ (1) representing the [9+2] structure consisting of a $\mathrm{Au}_{9}$ core and two gold atoms at the exo positions. The core units and the exo gold atoms are indicated by the shaded rectangles and the dotted circles, respectively.

${ }_{45}\left[\mathrm{Au}_{11}\left(\mathrm{Ph}_{2} \mathrm{P}\left(\mathrm{CH}_{2}\right)_{2} \mathrm{PPh}_{2}\right)_{6}\right]^{3+}$ by comparison with a simulated isotopic distribution pattern (see, ESI $\dagger$ ). Single-crystal X-ray analysis of $1-\left(\mathrm{SbF}_{6}\right)_{3}$ revealed a unique cluster structure composed of a $\mathrm{Au}_{9}$ core plus two gold atoms at the exo positions (Fig. 1). The exo atoms form triangles by sharing an 50 edge of the $\mathrm{Au}_{9}$ core. The $\mathrm{Au}_{9}$ core unit is apparently similar to previously known examples of butterfly-shaped clusters, although it has a slightly wider range of $\mathrm{Au}-\mathrm{Au}$ bond distances $(2.6294(8)-2.9709(8) \quad \AA)$ than $\left[\mathrm{Au}_{9}\left(\mathrm{PPh}_{3}\right)_{8}\right]^{3+}$ $(2.6745(9)-2.8804(12) \AA)^{3 \mathrm{~b}}$ and $\left[\mathrm{Au}_{9}\left(\mathrm{P}\left(p-\mathrm{C}_{6} \mathrm{H}_{4} \mathrm{OCH}_{3}\right)_{3}\right)_{8}\right]^{3+}$ $55(2.689(2)-2.899(4) \AA){ }^{3 a}$ This may reflect some distortion caused by the bridging of the exo gold atoms. The exo gold atoms have $\mathrm{Au}-\mathrm{Au}$ bond distances of 2.7769(9) and 2.8240(8) $\AA$, which lie in the range of the bond distances in the central butterfly unit. Each of the exo gold atoms of $\mathbf{1}$ is bonded to ${ }_{60}$ the two phosphine ligands and is situated at the tetrahedral centre, whereas the eight peripheral gold atoms of the $\mathrm{Au}_{9}$ core accommodate single phosphine ligands. The structure found in the solid state appeared essentially retained in solution. The ${ }^{31} \mathrm{P}$ NMR spectrum of $1-\left(\mathrm{SbF}_{6}\right)_{3}$ in $\mathrm{CD}_{2} \mathrm{Cl}_{2}$ ${ }_{65}$ showed three signals with an intensity ratio of $1: 1: 1$ (Figure $\mathrm{S} 2, \mathrm{ESI} \dagger)$, which were in agreement with the crystal structure.

$1-\left(\mathrm{SbF}_{6}\right)_{3}$ in dichloromethane was deep green in colour. Accordingly, the electronic absorption spectrum revealed a distinct band in the red region $(663 \mathrm{~nm})$ together with small 70 humps in the blue to UV region (460 and $390 \mathrm{~nm}$ ) (Fig. 2a). The intense low-energy absorption at $663 \mathrm{~nm}\left(\varepsilon_{\max }=8.9 \times 10^{4}\right.$ $\mathrm{L} \cdot \mathrm{cm}^{-1} \cdot \mathrm{mol}^{-1}$ ) was apparently observed as a single isolated 


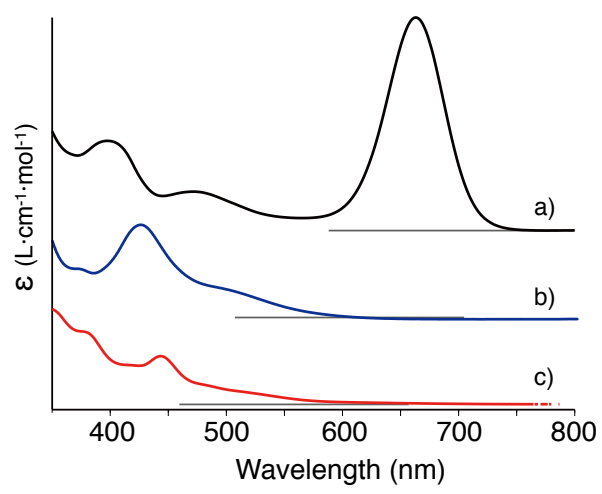

Fig. 2 Visible absorption spectra of a) $\left[\mathrm{Au}_{11}\left(\mathrm{Ph}_{2} \mathrm{P}\left(\mathrm{CH}_{2}\right)_{2} \mathrm{PPh}_{2}\right)_{6}\right]^{3+}(\mathbf{1})$, b) $\left[\mathrm{Au}_{11}\left(\mathrm{Ph}_{2} \mathrm{P}\left(\mathrm{CH}_{2}\right)_{3} \mathrm{PPh}_{2}\right)_{5}\right]^{3+}(2)$ and c) $\left[\mathrm{Au}_{9}\left(\mathrm{PPh}_{3}\right)_{8}\right]^{3+}$.

band, suggesting that it arises from a specific optical 5 transition. In contrast, the deca-ligated $\mathrm{Au}_{11}$ isomer with an icosahedron-based core structure, which is frequently found in the phosphine-coordinated gold cluster family, ${ }^{4,13}$ exhibited a completely different absorption spectrum. For example, $\left[\mathrm{Au}_{11}\left(\mathrm{Ph}_{2} \mathrm{P}\left(\mathrm{CH}_{2}\right)_{3} \mathrm{PPh}_{2}\right)_{5}\right]^{3+}(2)^{4 \mathrm{c}}$ had a relatively weak 10 absorption band at a high energy $(425 \mathrm{~nm})$ that overlapped a broad tail that decreased monotonically toward the red region (Fig. 2b). Such tail and humps spectral characteristics are ubiquitously observed for conventional "closed" gold clusters such as $\mathrm{Au}_{13}$ and $\mathrm{Au}_{25}$ that have icosahedron-based cores. ${ }^{1,5}$ It 15 should be noted that $\left[\mathrm{Au}_{9}\left(\mathrm{PPh}_{3}\right)_{8}\right]^{3+}$, which has a toroidal $\mathrm{Au}_{9}$ core and thus can be a model of the central substructure of $\mathbf{1},{ }^{9}$ had a similar tail-and-humps spectrum (c). Therefore, the gold atoms at the exo positions are likely to participate in the generation of the unique visible absorption of $\mathbf{1}$.

20 To obtain further insights into the correlation of optical property and geometrical structure, we performed quantum chemical calculations with the TURBOMOLE package. ${ }^{10}$ Fig. 3a (middle) shows the calculated energies of Kohn-Sham molecular orbitals (MOs) and the atomic orbital contributions 25 of $\left[\mathrm{Au}_{11}\left(\mathrm{H}_{2} \mathrm{P}\left(\mathrm{CH}_{2}\right)_{2} \mathrm{PH}_{2}\right)_{6}\right]^{3+}\left(\mathbf{1}^{\prime}\right)$ based on the crystal structure of 1 . In the electronic structure, HOMO, HOMO-1, and LUMO through LUMO+7 are preferentially composed of the 6 sp atomic orbitals of gold (green, Fig. 3a), thus forming the sp-band. The HOMO and the LUMO had appreciably 30 different energies from their adjacent orbitals (HOMO-1 and LUMO +1 , respectively). Fig. 3a (bottom, solid line) shows the theoretical absorption spectrum simulated by performing time-dependent density functional theory (TDDFT) calculation. The first (lowest-energy) excitation due to the 35 intraband $(\mathrm{sp} \rightarrow \mathrm{sp})$ HOMO $\rightarrow$ LUMO transition occurred at $2.20 \mathrm{eV}(564 \mathrm{~nm})$. This transition was dominant in the oscillator strength (see, ESI $\dagger$ ) and was observed as an isolated band in the simulated spectrum. It is thus assigned to the intense band at $663 \mathrm{~nm}$ of 1 (Fig. 2a and Fig. 3a (bottom, 40 dotted line)). The higher-energy transitions, such as HOMO$1 \rightarrow$ LUMO+2 $(3.10 \mathrm{eV})$ and HOMO-2 $\rightarrow$ LUMO+4 (3.64 $\mathrm{eV}$ ), contribute to the generation of the two absorption bands between 300 and $450 \mathrm{~nm}$, which are likely to correspond to the relatively weak humps at 460 and $390 \mathrm{~nm}$ in the spectrum 45 of 1 . Overall, the simulated spectrum of 1' agrees well with the experimental spectrum of $\mathbf{1}$, especially its spectral shape.

In contrast, the electronic structure of the spherical $\mathrm{Au}_{11}$
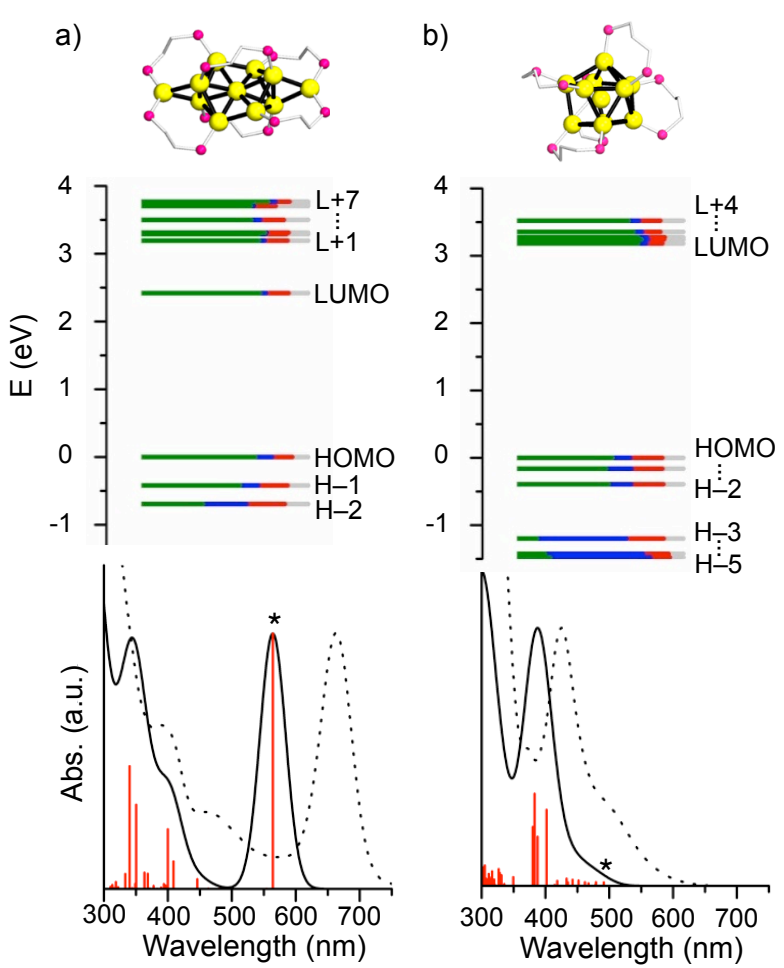

Fig. 3 Geometrical structures (top, Au and $\mathrm{P}$ atoms highlighted in yellow 50 and magenta, respectively), Kohn-Sham (KS) orbital energy level diagrams (middle), and theoretical absorption spectra (bottom, solid lines) of a) $\left[\mathrm{Au}_{11}\left(\mathrm{H}_{2} \mathrm{P}\left(\mathrm{CH}_{2}\right)_{2} \mathrm{PH}_{2}\right)_{6}\right]^{3+}\left(\mathbf{1}^{\prime}\right)$ and b) $\left[\mathrm{Au}_{11}\left(\mathrm{H}_{2} \mathrm{P}\left(\mathrm{CH}_{2}\right)_{3} \mathrm{PH}_{2}\right)_{5}\right]^{3+}\left(\mathbf{2}^{\prime}\right)$. Each KS orbital is relative to the HOMO energy and is drawn to indicate the relative contributions (line length with color labels) of the atomic 55 orbitals of $\mathrm{Au}(6 \mathrm{sp})$ in green, $\mathrm{Au}(5 \mathrm{~d})$ in blue, $\mathrm{P}(3 \mathrm{p})$ in red, and miscellaneous in gray. $\mathrm{H}-\mathrm{X}$ and $\mathrm{L}+\mathrm{Y}$ represent $\mathrm{HOMO}-\mathrm{X}$ and LUMO $+Y$, respectively. Experimental absorption profiles of $\mathbf{1}$ and $\mathbf{2}$ (dotted lines) are shown for comparison. The asterisks indicate the HOMO-LUMO transitions.

60 cluster $\left[\mathrm{Au}_{11}\left(\mathrm{H}_{2} \mathrm{P}\left(\mathrm{CH}_{2}\right)_{3} \mathrm{PH}_{2}\right)_{5}\right]^{3+}$ (2') differed remarkably. The HOMO and the LUMO were not so energetically isolated from their neighboring orbitals (Fig. $3 b$ (middle)). The LUMO to LUMO+4 were, though not degenerate, very close to each other. The TDDFT results reveal that the oscillator ${ }_{65}$ strength of the HOMO $\rightarrow$ LUMO transition $(2.52 \mathrm{eV}, 491 \mathrm{~nm})$ was small and close to those of several transitions with similar energies (see, ESI $\dagger$ ). Transitions with significant oscillator strengths were found at higher energies (e.g., $3.24 \mathrm{eV}, 383$ $\mathrm{nm}$ ), thereby giving rise to the tail-plus-humps profile (Fig. $3 \mathrm{~b}$ 70 (bottom, solid line)). This trend was reasonably well reproduced in the experimentally observed spectrum (Fig. 2b and Fig. 3b (bottom, dotted line)).

As described above, the HOMO-LUMO transition is primarily responsible for the appearance of low-energy 75 intense absorption band of 1. Fig. 4 depicts the HOMO and

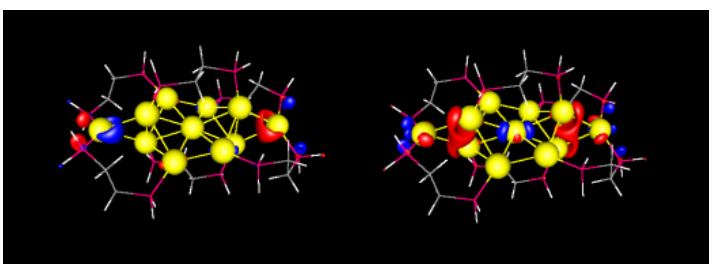

Fig. 4 LUMO (left) and HOMO (right) of $\left[\mathrm{Au}_{11}\left(\mathrm{H}_{2} \mathrm{P}\left(\mathrm{CH}_{2}\right)_{2} \mathrm{PH}_{2}\right)_{6}\right]^{3+}\left(\mathbf{1}^{\prime}\right)$. 
the LUMO of 1'. Both orbitals are located near the triangular $\mathrm{Au}_{3}$ units situated at both edges of the $\mathrm{Au}_{11}$ entity. The LUMO is found near the exo gold atoms, whereas the HOMO is located on the shared edges of the $\mathrm{Au}_{9}$ core and $\mathrm{Au}_{3}$ 5 triangles. Thus, the intense visible absorption band of $\mathbf{1}$ is mainly due to the core-to-exo intermetal transition.

In conclusion, we have determined the single-crystal structure and the optical property of a novel $\mathrm{Au}_{11}$ cluster (1), providing experimental evidence that the attachment of extra

10 metal atom(s) to the gold core moiety results in the generation of the unique electronic structure. Theoretical studies clearly indicate that the characteristic visible absorption is due to the HOMO-LUMO transition associated with the exo gold atoms attached to the metallic core. In contrast to conventional 15 "core-only" clusters, which are generally brown in colour, the [core+two] clusters exhibit unique colours and thus may be potential chromogenic modules. It should be possible to tune their optical properties (colour) by varying the exo metal atoms. Developing a method for the addition reaction of non20 gold atoms to core-only gold clusters for the rational design of "alloyed" [core+two] clusters is worthy of further investigation.

This work was partially supported by the MEXT, Grant-inAid for Scientific Research on Innovative Areas "Emergence 25 in Chemistry" (20111009) and Japan Science and Technology Agency (JST), Core Research for Evolutional Science and Technology (CREST) and Advanced Low Carbon Technology Research and Development Program (ALCA). We also thank Dr. K. Yoza (Bruker AXS) for crystallography.

\section{${ }_{30}$ Notes and references}

\$ Crystallographic data for 1-( $\left.\mathrm{SbF}_{6}\right)_{3} \cdot 5 \mathrm{EtOH}: \mathrm{C}_{166} \mathrm{H}_{174} \mathrm{Au}_{11} \mathrm{~F}_{18} \mathrm{O}_{5} \mathrm{P}_{12} \mathrm{Sb}_{3}$, $M=5494.57$, monoclinic, $a=18.066(2) \AA, b=27.709(4) \AA \AA a=$ $38.450(5) \AA, \alpha=90.00^{\circ}, \beta=102.908(2)^{\circ}, \gamma=90.00^{\circ}, V=18762(4) \AA^{3}, T$ $=90 \mathrm{~K}$, space group $C 2 / c, Z=4,49426$ reflections measured, 19177 35 independent reflections $\left(R_{\text {int }}=0.0629\right)$. The final $R_{l}$ value was 0.0571 ( $I$ $>2 \sigma(I))$. The final $w R\left(F^{2}\right)$ values were $0.1491(I>2 \sigma(I))$. The final $R_{l}$ value was 0.0996 (all data). The final $w R\left(F^{2}\right)$ value was 0.1794 (all data).

1 (a) Modern Supramolecular Gold Chemistry, ed, A. Laguna, WileyVCH, Weinheim, 2008; (b) K. P. Hall and D. M. P. Mingos, Prog. Inorg. Chem., 1984, 32, 237; (c) D. M. P. Mingos, T. Slee and Z. Y. Lin, Chem. Rev., 1990, 90, 383; (d) R. Jin, Nanoscale, 2010, 2, 343.

2 (a) P. D. Jadzinsky, G. Calero, C. J. Ackerson, D. A. Bushnell and R. D. Kornberg, Science, 2007, 318, 430; (b) M. W. Heaven, A. Dass, P. S. White, K. M. Holt and R. W. Murray, J. Am. Chem. Soc., 2008, 130, 3754; (c) M. Zhu, C. M. Aikens, F. J. Hollander, G. C. Schatz and R. Jin, J. Am. Chem. Soc., 2008, 130, 5883; (d) H. Qian, W. T. Eckenhoff, Y. Zhu, T. Pintauer and R. Jin, J. Am. Chem. Soc., 2010, 132, 8280 .

3 (a) C. E. Briant, K. P. Hall and D. M. P. Mingos, J. Chem. Soc., Chem. Commun., 1984, 290; (b) F. Wen, U. Englert, B. Gutrath and U. Simon, Eur. J. Inorg. Chem., 2008, 106; (c) M. Schulz-Dobrick and M. Jansen, Eur. J. Inorg. Chem., 2006, 4498.

4 (a) V. G. Albano, P. L. Bellon, M. Manassero and M. Sansoni, J. Chem. Soc., Chem. Commun., 1970, 1210; (b) F. A. Vollenbroek, J. J. Bour and J. W. A.Van der Velden, Rec. Tray. Chim. Pays-Bas, 1980, 99, 137; (c) J. M. M. Smits, J. J. Bour, F. A. Vollenbroek and P. T. Beurskens, J. Crystallogr. Spectrosc. Res. 1983, 13, 355; (d) R. C. B. Copley and D. M. P. Mingos, J. Chem. Soc., Dalton Trans., 1996, 479; (e) K. Nunokawa, S. Onaka, T. Yamaguchi, T. Ito, S. Watase and M. Nakamoto, Bull. Chem. Soc. Jpn., 2003, 76, 1601.

5 (a) C. E. Briant, B. R. C. Theobald, J. W. White, L. K. Bell and D. M. P. Mingos, J. Chem. Soc., Chem. Commun., 1981, 201; (b) Y. Shichibu, Y. Negishi, T. Watanabe, N. K. Chaki, H. Kawaguchi and
T. Tsukuda, J. Phys. Chem. C, 2007, 111, 7845; (c) Y. Shichibu and K. Konishi, Small, 2010, 6, 1216.

6 (a) J. W. A. van der velden, J. J. Bour, W. P. Bosman and J. H. Noordik, J. Chem. Soc., Chem. Commun., 1981, 1218; (b) J. W. A. van der Velden, J. J. Bour, J. J. Steggerda, P. T. Beurskens, M. Roseboom and J. H. Noordik, Inorg. Chem., 1982, 21, 4321; (c) A. Laguna, M. Laguna, M. C. Gimeno and P. G. Jones, Organometallics, 1992, 11, 2759; (d) B. K. Teo, X. B. Shi and H. Zhang, J. Am. Chem. Soc., 1992, 114, 2743; (e) G. M. T. Cheetham, M. M. Harding, J. L. Haggitt, D. M. P. Mingos and H. R. Powell, J. Chem. Soc., Chem. Commun., 1993, 1000; (f) Y. Kamei, Y. Shichibu and K. Konishi, Angew. Chem. Int. Ed., 2011, 50, 7442.

7 For recent DFT studies on gold clusters, see: (a) K. Nobusada and T. Iwasa, J. Phys. Chem. C, 2007, 111, 14279; (b) M. Walter, J. Akola, O. Lopez-Acevedo, P. D. Jadzinsky, G. Calero, C. J. Ackerson, R. L. Whetten, H. Grönbeck and H. Häkkinen, Proc. Natl. Acad. Sci. U.S.A., 2008, 105, 9157; (c) Y. Pei, Y. Gao, N. Shao and X. C. Zeng, J. Am. Chem. Soc., 2009, 131, 13619; (d) D. E. Jiang, K. Nobusada, W. Luo and R. L. Whetten, ACS Nano, 2009, 3, 2351; (e) ref. 2c.

8 a) P. A. Bates and J. M. Waters, Inorg. Chim. Acta, 1985, 98, 125; b) M. C. Brandys, M. C. Jennings and R. J. Puddephatt, J. Chem. Soc., Dalton Trans., 2000, 4601.

9 Butterfly and crown geometries are known for toroidal $\mathrm{Au}_{9}$ clusters. These two isomers in solution are reported in equilibrium with each other to show similar electronic spectral characteristics (ref. 1b).

10 TURBOMOLE V6.3 2011, a development of University of Karlsruhe and Forschungszentrum Karlsruhe GmbH, 1989-2007, TURBOMOLE GmbH, since 2007; available from http://www.turbomole.com.

13 (a) W. Jahn, J. Struct. Biol., 1999, 127, 106; (b) M. F. Bertino, Z.-M. Sun, R. Zhang and L.-S. Wang, J. Phys. Chem. B, 2006, 110, 21416; 95 (c) Y. Yanagimoto, Y. Negishi, H. Fujihara and T. Tsukuda, J. Phys. Chem. B, 2006, 110, 11511 . 


\section{Table of contents entry}

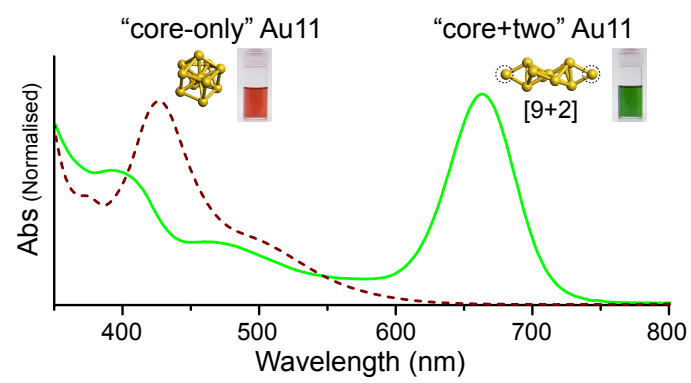

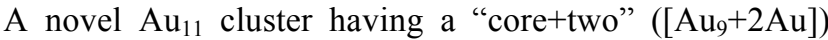
geometric structure showed an evidently different absorption spectrum from that of the "core-only" isomer. ${ }_{10}$ The role of the exo gold atoms was investigated theoretically. 